\title{
Solar energy harvesting for LoRaWAN-based pervasive environmental monitoring
}

\author{
Tommaso Addabbo ${ }^{1}$, Ada Fort ${ }^{1}$, Matteo Intravaia ${ }^{1}$, Marco Mugnaini ${ }^{1}$, Lorenzo Parri ${ }^{1}$, Alessandro \\ Pozzebon ${ }^{1}$, Valerio Vignoli ${ }^{1}$
}

${ }^{1}$ Department of Information Engineering and Mathematics, University of Siena, Via Roma 56, 53100 Siena, Italy

\begin{abstract}
The aim of this paper is to discuss the characterisation of a solar energy harvesting system to be integrated in a wireless sensor node, to be deployed on means of transport to pervasively collect measurements of Particulate Matter (PM) concentration in urban areas. The sensor node is based on the use of low-cost PM sensors and exploits LoRaWAN connectivity to remotely transfer the collected data. The node also integrates GPS localisation features, that allow to associate the measured values with the geographical coordinates of the sampling site. In particular, the system is provided with an innovative, small-scale, solar-based powering solution that allows its energy self-sufficiency and then its functioning without the need for a connection to the power grid. Tests concerning the energy production of the solar cell were performed in order to optimise the functioning of the sensor node: satisfactory results were achieved in terms of number of samplings per hour. Finally, field tests were carried out with the integrated environmental monitoring device proving its effectiveness.
\end{abstract}

\section{Section: RESEARCH PAPER}

Keywords: solar; energy harvesting; LoRaWAN; environmental monitoring; particulate matter

Citation: Tommaso Addabbo, Ada Fort, Matteo Intravaia, Marco Mugnaini, Lorenzo Parri, Alessandro Pozzebon, Valerio Vignoli, Solar energy harvesting for LoRaWAN-based pervasive environmental monitoring, Acta IMEKO, vol. 10, no. 2, article 16, June 2021, identifier: IMEKO-ACTA-10 (2021)-02-16

Section Editor: Giuseppe Caravello, Università degli Studi di Palermo, Italy

Received January 18, 2021; In final form May 5, 2021; Published June 2021

Copyright: This is an open-access article distributed under the terms of the Creative Commons Attribution 3.0 License, which permits unrestricted use, distribution, and reproduction in any medium, provided the original author and source are credited.

Corresponding author: Alessandro Pozzebon, e-mail: alessandro.pozzebon@unisi.it

\section{INTRODUCTION}

Energy self-sufficiency is one of the crucial requirements for the realisation of efficient real-time distributed monitoring infrastructures, in wide range of application fields, from environmental [1], [2] and cultural heritage monitoring [3], [4] to the aerospace [5] and the Smart Industry [6], [7] domains. Indeed, when developing a large number of wirelessly connected sensing devices, energy self-sufficiency means their usability as deployand-forget items, where any kind of manual intervention is reduced at minimum. Besides reducing power consumption, energy self-sufficiency mainly requires the presence of a continuous or semi-continuous source of energy that, when these devices are expected to be employed in motion, cannot be the power grid. For this reason, the only way to ensure the continuous presence of the adequate amount of energy to allow the sensing device functioning is the so-called energy harvesting, i.e., the presence of a source of renewable energy on-board. Among the various possible sources of energy, the most exploited is the solar one: indeed, several monitoring platforms have been provided with solar cells that are used to recharge onboard batteries or super-capacitors. Nevertheless, such a solution has to face in several cases limitations due to the large dimensions of the solar cells, to the limited amount of achievable power or to the inadequate exposition of the sensing device. Another factor influencing the performances of the energy harvesting system is the complexity of the sensing platform: indeed, the more power-hungry are the components, the more difficult is the design of the harvesting solution.

The aim of this paper is to propose the characterisation of a small scale solar-based energy harvesting system, designed to identify an efficient trade-off among dimensions and power efficiency. In order to demonstrate the validity of the proposed solution, it has been embedded in a wireless sensing device thought to be employed for distributed real-time environmental monitoring: in particular, the sensing device is provided with sensors for the measurement of Particulate Matter (PM), with a GPS module for localisation and tracking purposes and with Long Range Wide Area Network (LoRaWAN) connectivity. Such a device is expected to be employed within a Smart City context. While several city-scale air quality wireless monitoring 
infrastructures can be found in literature [8], [9], [10], this paper focuses on the realisation of a different typology of data acquisition architecture. Indeed, in the proposed solution, the sensor nodes are expected to be provided with localisation features [11] and then to be deployed on means of public transport. This approach is especially relevant since it allows to acquire data in a more pervasive way, bringing the measurement instrumentation in almost every spot of a city. At the same time, the scope of the paper is to propose a device to be employed in a "plug-and-play" fashion: the use of the photovoltaic source for the powering of the system goes specifically in this direction. Indeed, while on means of public transportation several sources of energy may be available, the connection of a new device may require structural modifications on the vehicle itself to wire the sensor node to the power source. Such modifications may be even more cumbersome if the sensor node is expected to be deployed outside the vehicle, as in the case of acquisition of environmental parameters. Conversely, the design of a totally autonomous system may allow its deployment without any kind of intervention on the vehicle: in its final configuration, the sensor node may be attached for example with a magnet to the vehicle chassis.

The choice of Long Range (LoRa) as the transmission technology comes from its ability to provide possibly the best compromise between performances and costs within the Smart City scenario [12], [13]. Indeed, the long transmission ranges allow to cover a large area with a relatively small number of Gateways. At the same time, thanks to the LoRaWAN protocol, a large number of end devices can be simultaneously managed thanks to multi-channel and Gateway redundancies. On the other side, costs are kept very low since no fee is required for the transmitting devices: such aspect may be crucial when the number of devices to be deployed is expected to grow. At the same time, the same LoRaWAN network may be exploited also for other activities, thus further reducing the costs. If compared with competing technologies, the benefits coming from the adoption of LoRaWAN can be better underlined. Starting from local area technologies like ZigBee, Bluetooth or WiFi, their short transmission range obviously prevents for using them for monitoring at a city scale since too many Gateways may be required. Moving to wide area technologies, cellular ones are of course more reliable than LoRa. However, they require a subscription for each device and this cost may be unsustainable with a growing number of devices: conversely, LoRaWAN may easily scale since no cost is required for connection, and the price of LoRa modules is in the order of few euros, notably lower than its concurrent cellular technology, i.e., NB-IoT. The same limitation is applied to the other well-known sub-GHz technology, SigFox. Indeed, such technology too requires the payment of a subscription for each device.

At the same time, the limitations that may come from the usage of LoRaWAN are not crucial for the proposed application scenario. Indeed, the $1 \%$ duty-cycle limitation is not influent on the acquisition of PM values that can be performed every 10-15 minutes, while the limited reliability of the connection may lead to the loss of some packets that are not relevant too for the purpose of the proposed system.

The rest of the paper is structured as follows: in section 2 some details related to the monitoring of PM concentrations are provided, while section 3 focuses on the state of the art related to solar-based energy harvesting solutions. Section 4 provides a description of the overall sensor node architecture while section 5 is devoted to the design of the solar harvesting system. Section
6 provides some field test results while in section 7 some conclusive remarks are presented.

\section{PARTICULATE MATTER MONITORING}

The term "Particulate Matter" (PM) encompasses a wide range of solid, organic, and inorganic particles and liquid droplets that are commonly found in air. In general, PM is composed of a wide range of different elements that change according to the specific environmental features [14], [15], but include sulphate, nitrates, ammonia, sodium chloride, black carbon, mineral dust, and water. PM is classified according to the dimensions of the single particles: we speak then of $\mathrm{PM}_{10}$ when the diameter of the particles is lower than 10 micron $\left(d_{\mathrm{PM} 10}<10 \mu \mathrm{m}\right)$ and of $\mathrm{PM}_{2.5}$ when the diameter is lower than 2.5 micron $\left(d_{\mathrm{PM} 2.5}<2.5 \mu \mathrm{m}\right)$.

Both typologies of PM can be easily inhaled by human beings, and a chronic exposition to this kind of pollutants can bring to the emergence of cardiovascular and respiratory diseases. In particular [16], $\mathrm{PM}_{10}$ can penetrate inside lungs, while $\mathrm{PM}_{2.5}$ can penetrate the lung barrier and enter the blood system, with even more harmful effects. For this reason, World Health Organisation has defined two thresholds for each type of particulate, that can be seen in Table 1 [16], that should not be overcome to safeguard the citizens' health.

PM levels are usually measured by public bodies which collect the data by means of fixed monitoring stations deployed in a limited number of spots: in general, only one or few monitoring stations are present in medium to large-sized cities. Moreover, data collected by these stations refer only to the area of the city where they are deployed, while they cannot provide a pervasive feedback on the PM levels in other parts of the city. This fact is mainly due to the high cost of this monitoring stations that prevents from deploying them in a large number across a large territory. Nevertheless, some low-cost PM sensors are currently available on the market: while their accuracy level is not comparable with the fixed monitoring stations, they can still provide an interesting feedback on the level of PM, in particular, for what concerns the overcoming of the daily and yearly thresholds. Moreover, these devices are characterised by small dimensions, and can be then integrated on portable data acquisition platforms that can be provided with the adequate connectivity to transfer the acquired data in real time to a remote data management centre. By deploying a large quantity of this kind of devices, a pervasive monitoring infrastructure can be then set up across a whole urban centre, thus perfectly fulfilling the paradigm of the Smart City [17], [18].

\section{SOLAR ENERGY HARVESTING}

In the last decades, due to the steadily growing number of power requiring devices and to the subsequent technology sustainability issues, light energy harvesting has attracted tremendous interest and has aroused a great research effort in the scientific community, resulting in a plethora of solar cell typologies [19], [20], [21], [22], each with different optical and mechanical properties, performances and cost.

Table 1. Particulate Matter Thresholds.

\begin{tabular}{ccc}
\hline & 24-hour mean & Annual mean \\
\hline $\mathrm{PM}_{2.5}$ & $25 \mathrm{mg} / \mathrm{m}^{3}$ & $10 \mathrm{mg} / \mathrm{m}^{3}$ \\
$\mathrm{PM}_{10}$ & $50 \mathrm{mg} / \mathrm{m}^{3}$ & $20 \mathrm{mg} / \mathrm{m}^{3}$ \\
\hline
\end{tabular}


Some studies [23], [24], [25], [26], [27], [28], [29] aim to enhance the performances under particular light spectrum conditions, mainly low-intensity indoor lighting, choosing materials with suitable absorption spectra. Other researches focus on extremely improving the efficiency by realising multijunction structures capable of absorbing energy in a wide frequency range [30], [31].

Crystalline (monocrystalline and polycrystalline) silicon [32] is surely the dominant technology for solar cells, representing a good compromise between performance and cost [20]. Excellent efficiencies over $25 \%$ are achieved by monocrystalline silicon technology [19], thanks to efficiency improving strategies, such as carrier recombination reduction through contact passivation [33], [34], [35], [36]. Even though these latest efficiency enhancing techniques are not commonly findable in the marketplace yet, monocrystalline silicon solar cells remain the preferable solution for powering a small outdoor electronic utility, like the application presented in this paper, with the minimum encumbrance and at a very reasonable cost.

\section{SENSOR NODE STRUCTURE}

The sensor node purpose is to periodically sample the amount of PM in the air and transmit this information over a LoRa radio channel.

In addition, also the GPS position of the node has to be acquired every time a sample is collected. The sensor is powered by a battery that is recharged by means of a crystalline silicon solar cell. The structure of the system is shown in Figure 1.

The main blocks that compose the node are the Communication and Control Unit (CCU), the particle sensor, the GPS module, a battery and a step-up DC-DC converter to manage the energy coming from the solar cells. The CCU has been developed ad-hoc (See Figure 2) and hosts a low power STM32L073 microcontroller (MCU) by STMicroelectronics, a LoRa transceiver (RFM95 by HopeRF) and a power management electronics to supply internal devices and charge a Li-Ion battery.

The power from the solar cells is elevated and stabilised by a step-up DC-DC converter (LTC3105 on an evaluation board) that hosts a start-up controller (from $250 \mathrm{mV}$ ) and a Maximum Power Point Controller (MPPC) that enables operation directly from low voltage power sources such as photovoltaic cells.

The MPPC set point can be selected depending on the solar cells used. If energy from solar cell is available, the battery

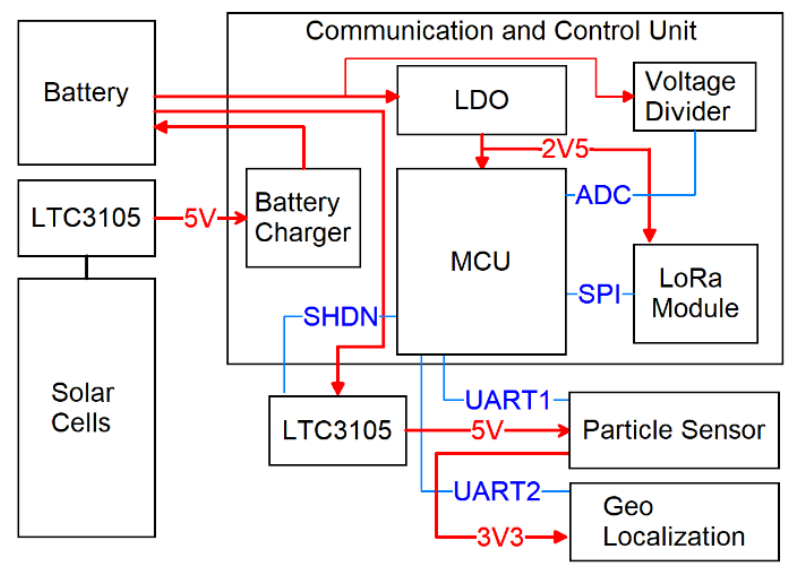

Figure 1. Sensor Node internal structure.

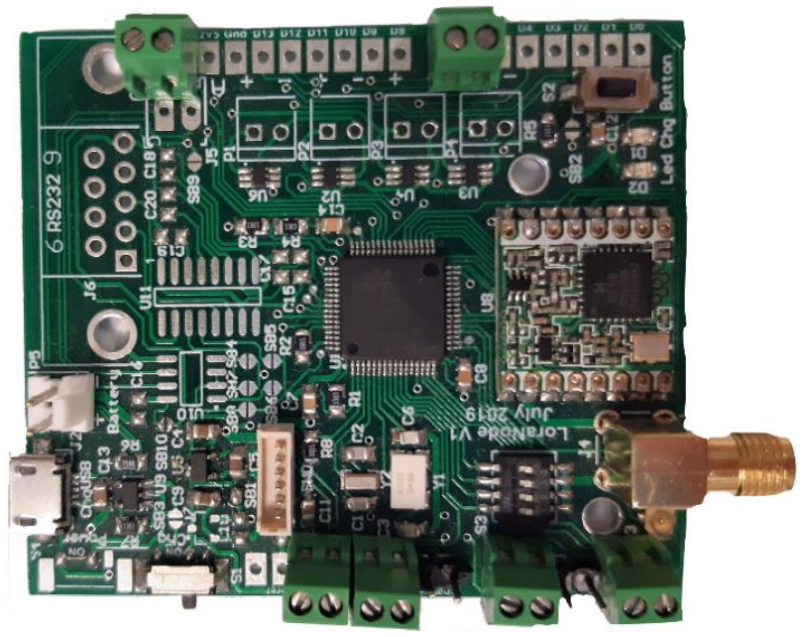

Figure 2. Communication and Control Unit

charger (STC4054 by STMicroelectronics) will recharge the battery. The MCU and the radio module are supplied by a $2.5 \mathrm{~V}$ LDO regulator, the voltage level of the battery is controlled by an ADC channel on the MCU and a voltage divider. The Particle sensor (HPMA115S0 by Honeywell), shown in Figure 3 requires $5 \mathrm{~V}$ to operate: this power source is generated by another LTC3105 module directly from the battery. This latter can be powered off by a specific shut down line from the MCU. The GPS module (MTK3339 by Adafruit) requires a power voltage of $3.3 \mathrm{~V}$, that is available as an output of the particle sensor.

Since the sensor node is expected to operate continuously without the need of connection to the power grid, a power strategy based on a strict duty-cycling was adopted. In particular, the system is expected to perform data sampling and transmission, and then to be put in sleep mode according to an adaptive duty-cycling policy that will be described in detail in section 5 .

\section{ENERGY HARVESTING AND POWER MANAGEMENT}

The sensor node is powered with a battery charged by a small solar harvester. The aim of this section is to foresee the maximum feasible duty cycle of the sensor node operations for not draining completely the battery, given the energy collected by the harvester. This problem can be formulated as the following condition:

$$
W_{H} \geq W_{\delta}(\delta)
$$

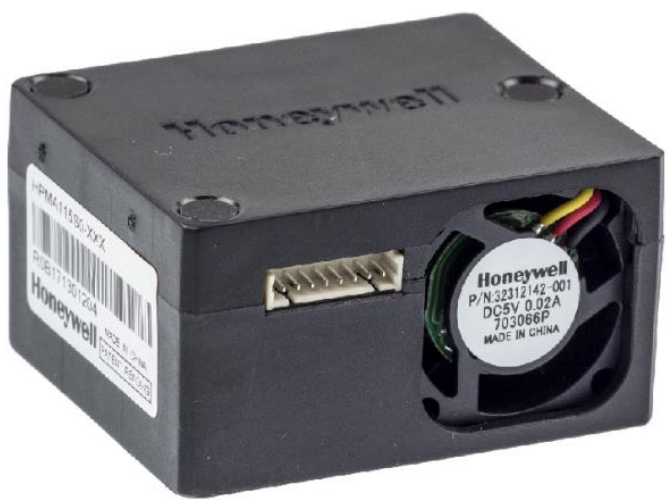

Figure 3. Honeywell HPMA115S0 Particulate Matter sensor. 
where $W_{\mathrm{H}}$ is the energy harvested over a day, while $W_{\delta}(\delta)$ is the sensor node energy consumption over a day, which in fact depends on the duty cycle $\delta$. Respecting condition (1) means to guarantee energy self-sufficiency to the sensor device, with no need for battery replacement.

Therefore, the first step is to assess the sensor node energy requirements, i.e. the quantity $W_{\delta}(\delta)$. Let us indicate with $t_{0}$ the time (in seconds) necessary for a complete operating sequence, made up of MCU acquisition, data transmission via LoRa and GPS localisation. The maximum number of operating sessions in an hour is given by:

$$
N=\left\lfloor\frac{3600}{t_{0}}\right\rfloor \text {. }
$$

In our case we have $t_{0}=10 \mathrm{~s}$ and thus $N=360$. Let $n$ be the desired number of operating sessions in an hour. Then the duty cycle is plainly given by:

$$
\delta=\frac{n}{N} \text {. }
$$

Now, let $W_{0}$ be the energy required for a single operating sequence. Considering the sensor and analog front-end powering, the microcontroller consumption in run mode, the LoRa module consumption in stand-by and transmission modes, and the GPS consumption, we obtained $W_{0} \approx 0.29 \mathrm{mWh}$ Using equation (3), the daily energy consumption for a fixed duty cycle is given by:

$$
W_{\delta}(\delta)=24 \cdot W_{0} \cdot n=24 \cdot W_{0} \cdot \delta \cdot N .
$$

Substituting $W_{\delta}(\delta)$ with $W_{H}$ in equation (4) yields the maximum feasible duty cycle:

$$
\delta_{\max }=\frac{W_{\mathrm{H}}}{24 \cdot W_{0} \cdot N} .
$$

The harvested energy $W_{\mathrm{H}}$ varies dramatically during the year and obviously is strongly dependent on the weather conditions. In our previous work [37], we proposed a theoretical evaluation of the quantity $W_{\mathrm{H}}$ over the year, calculating approximately the energy produced by a reference monocrystalline silicon solar cell [34]. In this paper, we present some recent experimental results on the energy harvested by a commercial monocrystalline silicon solar cell for outdoor use, produced by Seeed Studio (Figure 4). The producers attest that this solar module is capable of operating at a voltage of $5.5 \mathrm{~V}$ and a current of $100 \mathrm{~mA}$, resulting in a maximum power point (MPP) of $0.55 \mathrm{~W}^{1}$. The cell surface is $70 \times 55 \mathrm{~mm}^{2}$. The measurements were performed in Siena, Italy, during sunny or partially cloudy days in the first half of January 2021 (a complete characterisation of the solar cell behaviour throughout the whole year would require a long measuring campaign, and data are not available to date). In the next section, the employed measurement system for the solar cell

1 The producers do not mention explicitly the working conditions under which their solar modules were characterised. Usually, solar cell performances are evaluated under Standard Test Conditions (i.e. $25^{\circ} \mathrm{C}$ temperature, $1000 \mathrm{~W} / \mathrm{m}^{2}$ solar irradiance, 1.5 air mass).

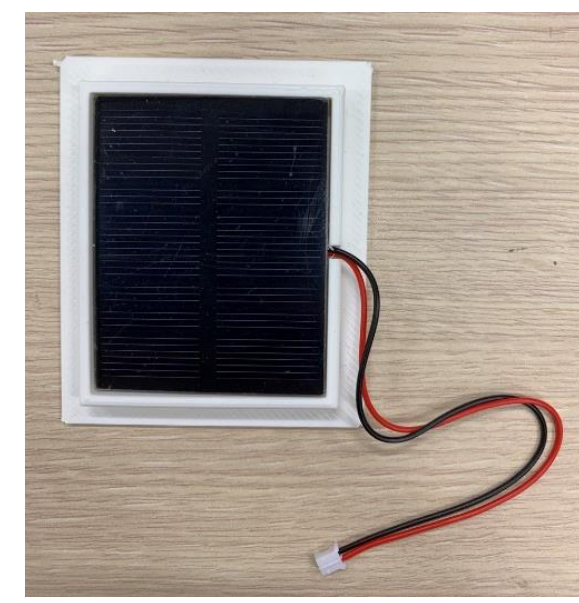

Figure 4. Selected monocrystalline solar module.

characterisation $^{2}$ is described; section 5.2 shows the results of the measurements.

\subsection{Solar cell characterisation method}

The circuitry employed for characterising the performances of the selected solar module is based on a solution proposed by Analog Devices. Figure 5 shows the circuit schematic.

Referring to Figure 5, the solar module to be characterised is connected to the ports labelled PV+ and PV- on the left. The lower branch is the voltage sensing part, made up of a simple voltage divider followed by an operational amplifier $(\mathrm{OA})$ in noninverting configuration. The overall voltage gain $G_{V}$ is given by:

$$
G_{V}=\frac{R 2}{R 1+R 2} \cdot\left(1+\frac{R 4}{R 3}\right) .
$$

The $R 4$ resistor is actually short-circuited because the solar module already outputs a voltage in the order of some Volts. The upper branch is the current sensing part: the current is converted into a voltage through the $1 \Omega$ resistor and then amplified by

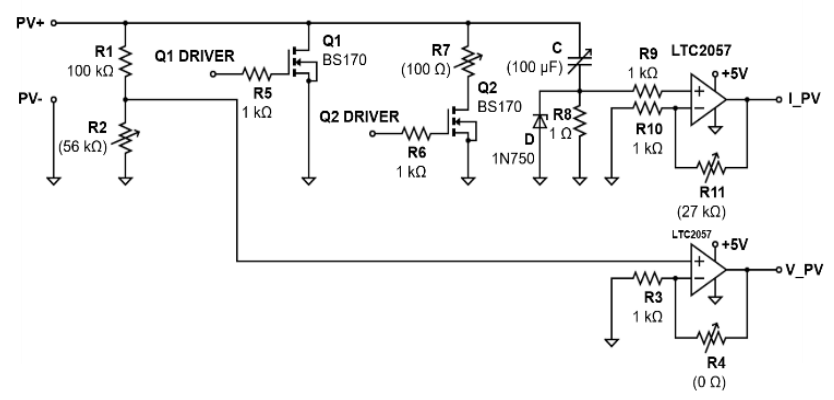

Figure 5. Solar cell characterisation circuit. For the varying elements, the value used for the experiments presented in this work is reported in brackets.
2 The term characterisation may be object of misunderstanding. In this context, we are only interested in evaluating the maximum power deliverable by the solar cell, we do not want to determine its parameters (open-circuit voltage, short-circuit current, fill factor) from the currentvoltage curve. Therefore, in the following, the term "characterisation" is referred to the evaluation of the cell maximum deliverable power. 
another non-inverting amplifier. Thus, the overall current gain $G_{I}$ is:

$$
G_{I}=1+\frac{R 11}{R 10} \text {. }
$$

This circuit is capable of scanning the current-voltage (IV) curve of the connected solar cell when MOSFET Q1 and MOSFET Q2 are conveniently driven. In detail, before starting the acquisition (idle state), Q1 is on and Q2 is on and therefore the solar cell is in short-circuit conditions, while the OA outputs are both zero. The measurement starts when Q1 and Q2 are switched off: when this happens, the current instantaneously flows through the capacitor $C$ and the current sensing $1 \Omega$ resistor. The voltage across the solar cell is still zero (short-circuit conditions), but now the short-circuit current is visible amplified on the current sensing OA output. The capacitor starts to charge towards the cell open-circuit voltage, which is actually never reached as an effect of the presence of the voltage divider. In this way, the solar cell IV characteristic is scanned and, in particular, the MPP is certainly touched at some points. Then, after the IV transient, Q2, which has a drain dissipative power resistor to limit the current, is switched on again. Finally, also Q1 is switched on to return back into the initial idle state.

The two OA outputs are sampled by a STM32L432KC microcontroller. The microcontroller acquires 500 samples $(250$ for the voltage and 250 for the current on two different ADC channels) at $125 \mathrm{ksps}$ per channel. The covered time interval is therefore $2 \mathrm{~ms}$, which is sufficient for sampling the signals of interest with a satisfying time resolution. The ADC has 12 bits and $3.3 \mathrm{~V}$ full-scale. The STM32L432KC also powers the two OA through an on-board $5 \mathrm{~V}$ output and drives Q1 and Q2 through $3.3 \mathrm{~V}$ tolerant general purpose input/output (GPIO) pins. A Raspberry PI powers the STM32L432KC and collects the data from it in JavaScript Object Notation (JSON) format. The data are available remotely on a web database.

This solution for solar cell characterisation presents some problems (as already mentioned, the open-circuit voltage is unreachable), but is more than sufficient for our application, since we are not interested in drawing the entire IV curve, but only in evaluating the maximum power deliverable by the cell. Furthermore, this solution exhibits two fundamental advantages: first, it is extremely low-cost; second, it is portable, as it exploits the response of the solar cell itself to a load impedance variation, and thus there is no need for a precision voltmeter or a signal generator (or for a more complex and power consuming current generator circuit), usually present for setting the cell current and measuring the voltage in more common solar cell characterisation methods.

\subsection{Solar cell characterisation results}

Figure 6 shows the current and voltage variations on the cell during an acquisition cycle (i.e. the IV transient provoked by switching off Q1 and Q2, as explained in the previous section). As it can be seen, the cell passes from being short-circuited to an open-circuit condition. The resulting power curve (Figure 7) assumes the bell shape typical of a solar cell. The specific curves in Figure 6 and Figure 7 were obtained in laboratory testing the circuit under a white LED (3500 K colour temperature) and are only meant to demonstrate qualitatively the circuit functionality.

The measurements were performed in Siena, Italy, throughout sunny or partially cloudy days in January 2021. The characterisation system was placed in a realistic position, exposed to the sun during most of the day but with some trees and other

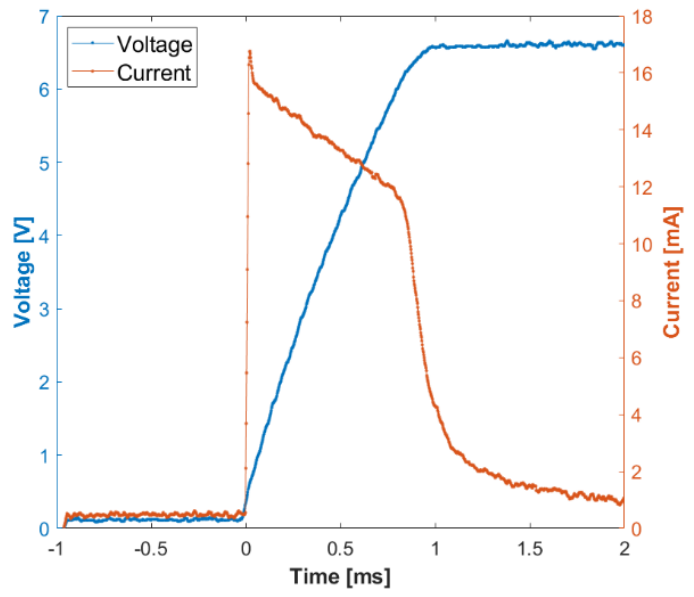

Figure 6. Solar cell current and voltage variations during an IV acquisition cycle: laboratory test under white LED.

obstacles likely present in the actual sensor usage. An acquisition was performed every minute. As an example, Figure 8 shows the cell maximum achievable power measured on 27th January 2021. The wells are due to the presence of obstacles (e.g. around midday some trees covered the solar module).

The total energy collected during the examined days (that is $W_{\mathrm{H}}$, see the introduction of section 5) oscillates between a minimum of $400 \mathrm{~mW} \mathrm{~h}$ in partially cloudy days and a maximum of $1 \mathrm{Wh}$. Considering on average $W_{\mathrm{H}} \approx 700 \mathrm{mWh}$, the corresponding maximum feasible duty cycle, calculated through equation (5), is:

$$
\delta_{\text {max }} \approx 30 \% \text {. }
$$

This result, put into equation (3), corresponds to about 100 sensor node acquisitions per hour, which is more than decent, considering that December and January are the worst months of the year for solar energy harvesting. However, it is clear that this performance assessment is not valid for heavily cloudy or rainy days, in which the energy production falls sharply (the energy produced on 9th January 2021 and 10th January 2021, which were completely sunless, was $20 \mathrm{~mW}$ h in total). For this reason, we are driving the future development of the powering of the sensor node towards a multi-source energy harvesting approach,

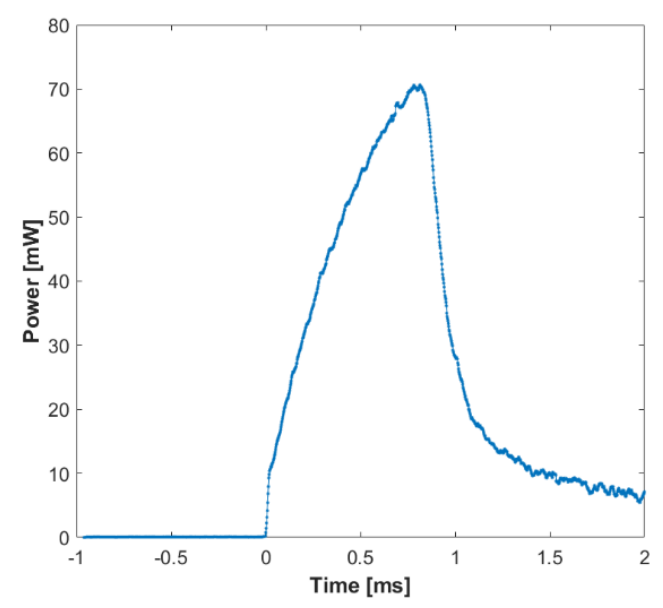

Figure 7. Power curve corresponding to current and voltage reported in Figure 6. 


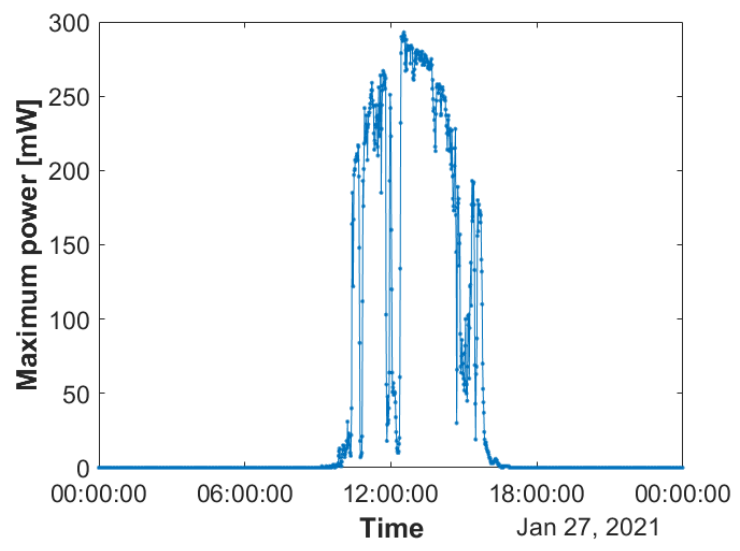

Figure 8. Solar cell maximum power production on 27th January 2021 in Siena, Italy.

adding, along with the solar harvester, a piezoelectric harvester for collecting energy also from mechanical vibrations and even from rainfall [38].

\section{TESTS AND MEASUREMENTS}

The performances of the system were tested in a real environment: in particular, the sensor node was placed for 1 week on the facade of the Department of Information Engineering and Mathematics of the University of Siena, Italy (See Figure 9), acquiring $\mathrm{PM}_{10}$ and $\mathrm{PM}_{2.5}$ values each 15 minutes. During each sampling, 10 values were acquired and then their mean value was transmitted by means of LoRaWAN protocol to a LoRaWAN Gateway positioned inside the building.

The PM sensor was characterised only in static conditions (no significant vibration is present) since the idea in the real scenario is to acquire the measurement only when the vehicle is still. Indeed, in its final configuration the node is expected to integrate an accelerometer that will be exploited to detect whether the vehicle is moving or not. The LoRaWAN transmission is then performed too in this phase since the whole data acquisition and transmission task requires less than $2 \mathrm{~s}$, avoiding thus possible additional issues due to the set up of a radio channel in nonstationary conditions.

In order to verify the operation of the system, the sampled values were compared with the ones available on the website of the Regional Environmental Protection Agency of Tuscany Region (ARPAT), which owns a set of fixed monitoring stations deployed across the whole territory of Tuscany. In particular, daily average values are available on ARPAT website: for this reason, for the acquired values the daily mean value was

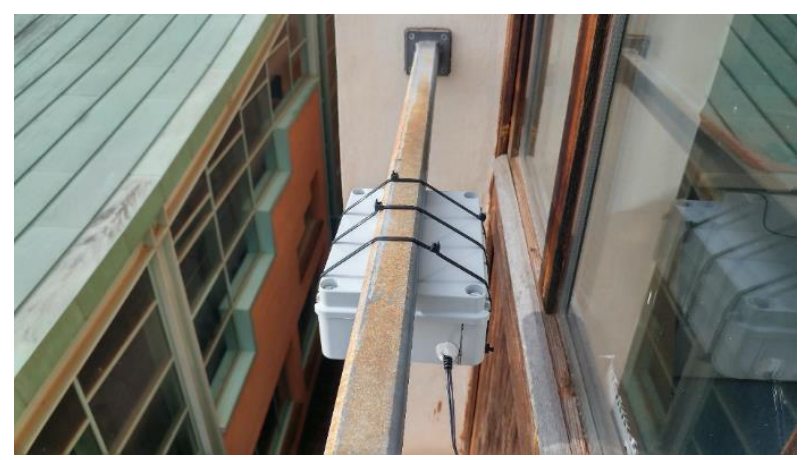

Figure 9. Sensor node testing setup.

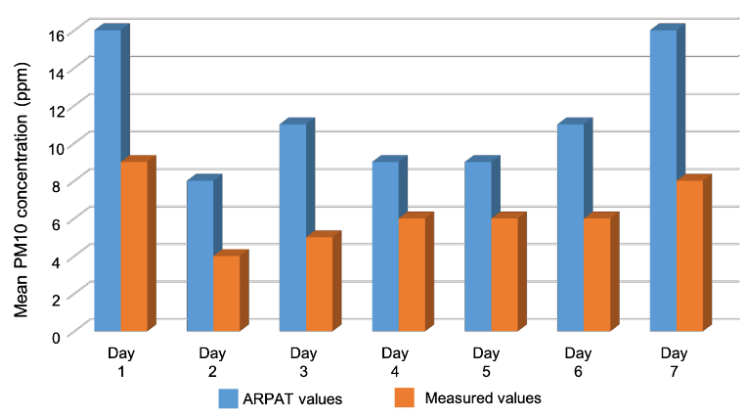

Figure 10. Comparison between daily mean PM10 concentrations provided by ARPAT and measured by the system.

calculated. The values were compared with the ones acquired by the fixed station positioned in Viale Bracci, Siena, Italy, which is the closest one to the University building, at a distance of $2.5 \mathrm{~km}$. A deployment close to this fixed station was not possible due to security reasons.

Figure 10 shows the daily mean values of $\mathrm{PM}_{10}$ concentrations measured at the fixed station by ARPAT and by the system described in this work, positioned on the University building. Even if the two values are notably different, this is due to the deployment site: while the ARPAT fixed station is positioned close to the very busy road that leads to the Siena hospital, the University building is positioned in a limited traffic area located in a peripheral part of the Historic Centre of Siena. Nevertheless, the effectiveness of the system can be noticed, since the trends of the two values all week long are almost similar: in particular, the values measured by the system are always almost half of the ones provided by ARPAT.

An important comment has to be done: a low-cost sensor has been used in the realisation of the system, and its accuracy level cannot be compared with the professional, and then very expensive, measurement platforms used by ARPAT. Nevertheless, looking at the values measured by the system, it is evident that the proposed solution can still be useful to collect data about PM in a more pervasive way, even if with a lower level of accuracy. In this sense, the proposed solution is not expected to replace the existing fixed measurement stations but mainly as system to enrich the knowledge about the different levels of PM that may be recorded in correspondence of different environmental conditions.

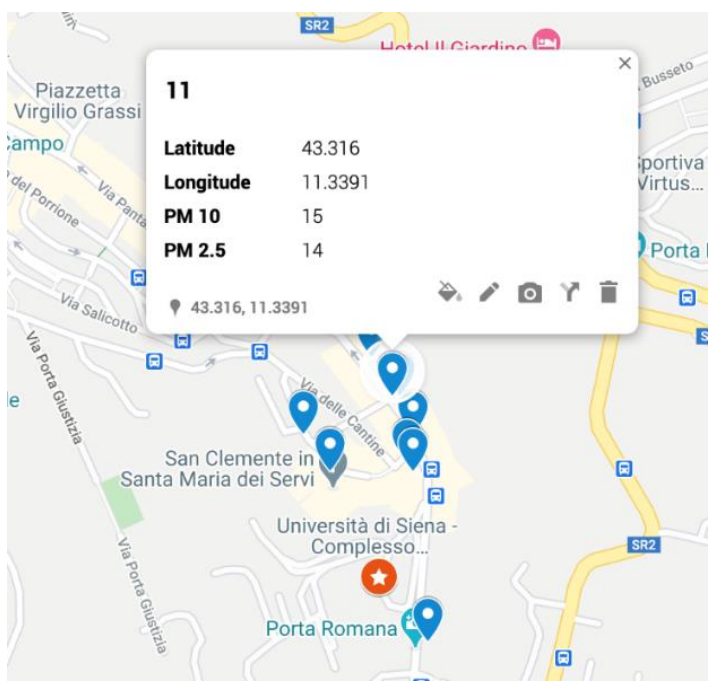

Figure 11 : Geographical data visualisation. 
Following the system characterisation performed in a controlled environment (i.e., the Department facade), a geographical data acquisition campaign was carried out, measuring $\mathrm{PM}_{2.5}$ and $\mathrm{PM}_{10}$ concentrations along the roads of a wide area within the historic centre of Siena. For this purpose, a Dragino LoRaWAN Gateway was placed on the front facade of the Department building, in the same spot that was used for the deployment of the sensor node in the previous experimentation. PM measurements were associated with the latitude and longitude values acquired by the GPS module: these values were then used to set up a data visualisation tool by means of Google Maps services. The measured values show an increase in the narrower alleys where vehicular traffic was more consistent. A screenshot of the acquired data visualisation tool, with the measurements related to one of the positions, is shown in Figure 11. Blue markers represent the spots where measurements were acquired while the red star shows the Gateway position.

\section{CONCLUSIONS}

The aim of this paper was to propose the architecture of a self-powered LoRaWAN sensor node for the pervasive measurement of PM concentrations in urban areas. According to the presented results, the system is able to operate autonomously exploiting an energy harvesting system based on the use of a small low-cost monocrystalline solar cell. In particular, the experimentation carried out demonstrated how the energy provided by the solar harvester is sufficient to guarantee around a hundred samplings per hour during winter, when solar energy production is at its minimum. Moreover, the addition of a mechanical vibration energy harvester is under evaluation as a future development, to enable a multi-source energy harvesting approach which would improve the energy production during sparsely lit days. At the same time, the system can sample the PM concentrations by means of a low-cost sensor, transmitting them to a LoRaWAN Gateway together with the geographic coordinates of the sampling location. By positioning the measurement system on means of public transport and combining these two data, PM levels may be measured across a large area and the level differences related to different areas of an urban centre may be identified. Moreover, the energy selfsufficiency feature may allow an easy deployment of the device on the vehicles, without the need for setting up wires to connect the node to external power sources as for example the vehicle batteries.

Together with the energy harvesting system, also a prototype of the measurement system was tested: preliminary tests were carried out in a controlled environment, and the acquired values were compared with the certified ones, provided by a public body, proving the consistence of the measured parameters. Following this preliminary step, the whole platform was tested for distributed data acquisition along city roads in Siena, thus in a real application scenario. The acquired results showed the effectiveness of the proposed solution.

\section{REFERENCES}

[1] F. Leccese, M. Cagnetti, A. Calogero, D. Trinca, S. di Pasquale, S. Giarnetti, I. Cozzella, A new acquisition and imaging system for environmental measurements: An experience on the Italian cultural heritage, Sensors, vol. 14, 2014, no. 5, pp. 9290-9312. DOI: $10.3390 / \mathrm{s} 140509290$

[2] A. Pozzebon, I. Cappelli, A. Mecocci, D. Bertoni, G. Sarti, F. Alquini, A wireless sensor network for the real-time remote measurement of aeolian sand transport on sandy beaches and dunes, Sensors, vol. 18, 2018, no. 3, p. 820 .

DOI: $\underline{10.3390 / \mathrm{s} 18030820}$

[3] F. Leccese, M. Cagnetti, S. Tuti, P. Gabriele, E. De Francesco, R. Đurovic-Pejcev, A. Pecora, Modified leach for Necropolis scenario, IMEKO International Conference on Metrology for Archaeology and Cultural Heritage, Lecce, Italy, 23-25 October 2017, pp. 442-447. Online [Accessed 18 June 2021]

https://www.imeko.org/publications/tc4-Archaeo-

2017/IMEKO-TC4-ARCHAEO-2017-088.pdf

[4] F. Lamonaca, C. Scuro, P. F. Sciammarella, R. S. Olivito, D. Grimaldi, D. L. Carnì, A layered IoT-based architecture for a distributed structural health monitoring system, Acta IMEKO, vol. 8 (2019), no. 2, pp. 45-52.

DOI: $10.21014 /$ acta imeko.v8i2.640

[5] F. Leccese, M. Cagnetti, S. Sciuto, A. Scorza, K. Torokhtii, E. Silva, Analysis, design, realization and test of a sensor network for aerospace applications, I2MTC 2017 - 2017 IEEE International Instrumentation and Measurement Technology Conference, Turin, Italy, 22-25 May 2017, pp. 1-6. DOI: $10.1109 /$ I2MTC.2017.7969946

[6] T. Addabbo, A. Fort, M. Mugnaini, L. Parri, S. Parrino, A. Pozzebon, V. Vignoli, A low power IoT architecture for the monitoring of chemical emissions, Acta IMEKO, vol. 8 (2019), no. 2, pp. 53-61. DOI: $10.21014 /$ acta imeko.v8i2.642

[7] L. Angrisani, U. Cesaro, M. D'Arco, O. Tamburis, Measurement applications in Industry 4.0: the case of an IoT-oriented platform for remote programming of automatic test equipment, Acta IMEKO, vol. 8 (2019), no. 2, pp. 62-69.

DOI: $10.21014 /$ acta imeko.v8i2.643

[8] K. Zheng, S. Zhao, Z. Yang, X. Xiong, W. W. Xiang, Design and implementation of LPWA-based air, IEEE Access, 2016, no. 4, pp. 3238-3245.

DOI: $10.1109 /$ ACCESS.2016.2582153

[9] G. B. Fioccola, R. Sommese, I. Tufano, R. C. a. G. Ventre, Polluino: An efficient cloud-based management of IoT devices for air quality monitoring, in IEEE 2nd International Forum on Research and Technologies for Society and Industry Leveraging a better tomorrow (RTSI), Bologna, Italy, 7-9 September 2016, pp. 1-6.

DOI: $10.1109 /$ RTSI.2016.7740617

[10] A. Candia, S. N. Represa, D. Giuliani, M. ç. Luengo, A. A. Porta, L. A. Marrone, Solutions for SmartCities: proposal of a monitoring system of air quality based on a LoRaWAN network with low-cost sensors, in Congreso Argentino de Ciencias de la Informatica y Desarrollos de Investigacion (CACIDI), Buenos Aires, Argentina, 28-30 November 2018, pp. 1-6.

DOI: $10.1109 / C A C I D I .2018 .8584183$

[11] T. Addabbo, A. Fort, M. Mugnaini, L. Parri, A. Pozzebon, V. Vignoli, Smart Sensing in Mobility: a LoRaWAN Architecture for Pervasive Environmental Monitoring, in IEEE 5th International forum on Research and Technology for Society and Industry (RTSI), Firenze, 9-12 September 2019, pp. 421-426. DOI: $10.1109 /$ RTSI.2019.8895563

[12] D. Magrin, M. Centenaro, L. Vangelista, Performance evaluation of LoRa networks in a smart city scenario, 2017 IEEE International Conference on Communications (ICC) Paris, France, 21-25 May 2017, pp. 1-7. DOI: $\underline{10.1109 / \text { ICC.2017.7996384 }}$

[13] P. J. Basford, F. M. Bulot, M. Apetroaie-Cristea, S. J. Cox, S. J. Ossont, LoRaWAN for smart city IoT deployments: A long term evaluation, Sensors, vol. 20, 2020, no. 3. DOI: $\underline{10.3390 / \mathrm{s} 20030648}$

[14] C. Perrino, F. Marcovecchio, L. Tofful, S. Canepari, Particulate matter concentration and chemical composition in the metro system of Rome, Italy, Environmental Science and Pollution Research, 2015, pp. 9204-9214. DOI: $10.1007 / \mathrm{s} 11356-014-4019-9$

[15] B. Zeb, K. Alam, A. Sorooshian, T. Blaschke, I. Ahmad, I. Shahid, On the morphology and composition of particulate matter in an 
urban environments, Aerosol and air quality research, 2018, p. 1431. DOI: $10.4209 /$ aaqr.2017.09.0340

[16] World Health Organization, Ambient (outdoor) air pollution Key Facts. Online [Accessed 18 June 2021] https://www.who.int/news-room/fact-sheets/detail/ambient(outdoor)-air-quality-and-health

[17] T. Nam, T. A. Pardo, Conceptualizing smart city with dimensions of technology, people, and institutions, in Proc. of the 12th annual international digital government research conference: digital government innovation in challenging times, College Park Maryland, USA 12-15 June 2011, pp. 282-291.

DOI: $\underline{10.1145 / 2037556.2037602}$

[18] M. Cerchecci, F. Luti, A. Mecocci, S. Parrino, G. Peruzzi, A Pozzebon, A low power Io'T sensor node architecture for waste management within smart cities context, Sensors, 2018, p. 1282. DOI: $10.3390 / \mathrm{s} 18041282$

[19] M. Green, E. Dunlop, J. Hohl-Ebinger, M. Yoshita, N. Kopidakis, X. Hao, Solar cell efficiency tables (version 57), Prog Photovolt Res Appl., vol. 29, 2021, pp. 3-15. DOI: $10.1002 / \mathrm{pip} .3371$

[20] M. H. Shubbak, Advances in solar photovoltaics: Technology review and patent trends, Renewable and Sustainable Energy Reviews, vol. 115, 2019, p. 109383. DOI: $10.1016 /$ i.rser.2019.109383

[21] S. Biswas, H. Kim, Solar Cells for Indoor Applications: Progress and Development, Polymers, vol. 12, 2020, p. 1338. DOI: $10.3390 /$ polym12061338

[22] S. Chowdhury, M. Kumar, S. Dutta, J. Park, J. Kim, S. Kim, M. Ju, Y. Kim, Y. Cho, E. Cho, J. Yi, High-efficiency Crystalline Silicon Solar Cells: A Review, New \& Renewable Energy, vol. 15, 2019, pp. 36-45.

DOI: $10.1039 /$ C5EE03380B

[23] P. Vincent, S.-C. Shin, J. S. Goo, Y.-J. You, B. Cho, S. Lee, D.-W. Lee, S. R. Kwon, K.-B. Chung, J.-J. Lee, J.-H. Bae, J. W. Shim, H. Kim, Indoor-type photovoltaics with organic solar cells through optimal design, Dyes and Pigments, vol. 159, 2018, pp. 306-313. DOI: $10.1016 /$ i.dyepig.2018.06.025

[24] S. Kim, M. A. Saeed, S. H. Kim, J. W. Shim, Enhanced hole selecting behavior of WO3 interlayers for efficient indoor organic photovoltaics with high fill-factor, Applied Surface Science, vol. 527, 2020, p. 146840. DOI: $10.1016 /$ j.apsusc. 2020.146840

[25] S. Biswas, Y.-J. You, Y. Lee, J. W. Shim, H. Kim, Efficiency improvement of indoor organic solar cell by optimization of the doping level of the hole extraction layer, Dyes and Pigments, vol. 183, 2020, p. 108719.

DOI: $10.1016 /$ j.dyepig.2020.108719

[26] A. S. Teran, E. Moon, W. Lim, G. Kim, I. Lee, D. Blaauw, J. D. Phillips, Energy Harvesting for GaAs Photovoltaics Under LowFlux Indoor Lighting Conditions, IEEE Transactions on Electron Devices, vol. 63, no. 7, 2016, pp. 2820-2825. DOI: $10.1109 /$ TED.2016.2569079

[27] I. Mathews, P. J. King, F. S. a. R. Frizzell, Performance of III-V Solar Cells as Indoor Light Energy Harvesters, IEEE Journal of Photovoltaics, vol. 6, no. 1, 2016, pp. 230-235.

DOI: $10.1109 / \mathrm{JPHOTOV} .2015 .2487825$

[28] C.-Y. Chen et al. (40 authors), Performance Characterization of Dye-Sensitized Photovoltaics under Indoor Lighting, The Journal of Physical Chemistry Letters, vol. 8, 2017, pp. 1824-1830. DOI: $10.1021 /$ acs.jpclett.7b00515

[29] Ming-Chi Tsai, Chin-Li Wang, Chiung-Wen Chang, Cheng-Wei Hsu, Yu-Hsin Hsiao, Chia-Lin Liu, Chen-Chi Wang, Shr-Yau Lina, Ching-Yao Lin, A large, ultra-black, efficient and costeffective dye-sensitized solar module approaching $12 \%$ overall efficiency under 1000 lux indoor light, Journal of Materials
Chemistry A, vol. 6, 2018, pp. 1995-2003.

DOI: $10.1039 /$ C7TA09322E

[30] P. Colter, B. Hagar, S. Bedair, Tunnel Junctions for III-V Multijunction Solar Cells Review, Crystals, 2018, p. 445. DOI: $10.3390 /$ cryst8120445

[31] J. Geisz, M. Steiner, N. Jain, K. Schulte, R. France, W. McMahon, E. Perl, D. Friedman, Building a Six-Junction Inverted Metamorphic Concentrator Solar Cell, IEEE Journal of Photovoltaics, 2017, pp. 1-7. DOI: $10.1109 /$ JPHOTOV.2017.2778567

[32] S. Chowdhury, M. Kumar, S. Dutta, J. Park, J. Kim, S. Kim, M. Ju, Y. Kim, Y. Cho, E.-C. Cho, J. Yi, High-efficiency Crystalline Silicon Solar Cells: A Review, New \& Renewable Energy, vol. 15, 2019, pp. 36-45.

DOI: $\underline{10.7849 / \mathrm{ksnre} .2019 .3 .15 .3 .036}$

[33] A. Morisset, R. Cabal, V. Giglia, A. Boulineau, E. D. Vito, A. Chabli, S. Dubois, J. Alvarez, J.-P. Kleider, Evolution of the surface passivation mechanism during the fabrication of ex-situ doped poly-Si(B)/SiOx passivating contacts for high-efficiency cSi solar cells, Solar Energy Materials and Solar Cells, vol. 221, 2021, p. 110899.

DOI: $\underline{10.1016 / \text { j.solmat.2020.110899 }}$

[34] A. Richter, J. Benick, F. Feldmann, A. Fell, M. Hermle, S. Glunz, $\mathrm{n}$-Type Si solar cells with passivating electron contact: Identifying sources for efficiency limitations by wafer thickness and resistivity variation, Solar Energy Materials and Solar Cells, no. 173, 2017, pp. 96-105. DOI: $10.1016 /$ j.solmat.2017.05.042

[35] D. Attafi, A. Meftah, R. Boumaraf, M. Labed, N. Sengouga, Enhancement of silicon solar cell performance by introducing selected defects in the $\mathrm{SiO} 2$ passivation layer, Optik, vol. 229, 2021, p. 166206.

DOI: $\underline{10.1016 / \text { i.ijleo.2020.166206 }}$

[36] F. Meyer, A. Savoy, J. J. D. Leon, M. Persoz, X. Niquille, C. Allebé, S. Nicolay, F.-J. Haug, A. Ingenito, C. Ballif, Optimization of front $\mathrm{SiNx} /$ ITO stacks for high-efficiency two-side contacted c-Si solar cells with co-annealed front and rear passivating contacts, Solar Energy Materials and Solar Cells, vol. 219, 2021, p. 110815. DOI: $10.1016 /$ j.solmat.2020.110815

[37] T. Addabbo, A. Fort, M. Intravaia, M. Mugnaini, L. Parri, A. Pozzebon, V. Vignoli, Pervasive environmental monitoring by means of self-powered particulate matter LoRaWAN sensor nodes, in 24th IMEKO TC4 International Symposium and 22nd International Workshop on ADC and DAC Modelling and Testing, Palermo, Italy, 14-16 September 2020. Online [Accessed 18 June 2021] https://www.imeko.org/publications/tc4-2020/IMEKO-TC42020-20.pdf

[38] G. Acciari, M. Caruso, M. Fricano, A. Imburgia, R. Miceli, P. Romano, G. Schettino, F. Viola, Experimental investigation on different rainfall energy harvesting structures, in Thirteenth International Conference on Ecological Vehicles and Renewable Energies (EVER), Monte-Carlo, Monaco, 10-12 April 2018, pp. 1 5 . DOI: $10.1109 /$ EVER.2018.8362346

[39] P. Löper, D. Pysch, A. Richter, M. Hermle, S. Janz, M. Zacharias, S. Glunz, Analysis of the temperature dependence of the opencircuit voltage, Energy Procedia, no. 27, 2012, pp. 135-142. DOI: $10.1016 /$ j.egypro.2012.07.041

[40] P. Peumans, A. Yakimov, S. R. Forrest, Small molecular weight organic thin-film photodetectors and solar cells, Journal of Applied Physics, no. 93(7), 2003, pp. 3693-3723. DOI: $\underline{10.1063 / 1.1534621}$ 